\title{
Dividing of metal and plastic components of printed circuit boards
}

\author{
Jiri Krenek ${ }^{1}$, Dagmar Janacova ${ }^{1 *}$, Ondrej Liska ${ }^{2}$, Vladimir Vasek ${ }^{1}$ and Oldrich Suba ${ }^{3}$ \\ ${ }^{1}$ Tomas Bata Univerzity in Zlín, Faculty of Applied Informatics, nám. T.G.Masaryka 5555, 76001 Zlín, Czech Republic \\ 2 Technical University of Kosice, Faculty of Mechanical Engineering, Department of Automation, Control and Human Machine \\ Interaction, Letná 9, 04200 Košice, Slovakia \\ ${ }^{3}$ Tomas Bata Univerzity in Zlín, Faculty of Technology, nám. T.G.Masaryka 5555, 76001 Zlín, Czech Republic
}

\begin{abstract}
This paper contents one possibility of PCB separation due to the temperature due to the different thermal expansion of the metal path and the plastic from which the boards are made. Using the knowledge from the literary study and the simulation environments used, we have reached the maximum analysis of the problem. The separation of metal and plastic may occur due to temperature changes if the temperature difference is sufficient. We have carried out a study of printed circuit board production so we can choose the appropriate path of separation. Furthermore, we calculated the shear stress size required to tear the conductive copper paths from the epoxy resin. The temperature field in a two-layer board was modeled in the FEMLAB and Pro/ENGINEER programming environments. From the simulated temperature field simulations, conclusions can be drawn that accurately describe the condition and characteristics of materials subjected to heat shock. They derived the resulting relationship for calculating the resulting shear stress needed to separate the conductive paths and plastic materials of the PCB. In our own experiments, we used several ways to heat PCBs. The temperature is also sufficient for the separation of tin. After using the mechanical separation of the components, they were dropped from the PCB. Mechanical separation was also used when removing conductive paths. This separation is effective, but in the newer types of PCBs, the cyclical effects of thermal shock have to be applied to the separation of copper paths. Laboratory tests have demonstrated the viability of the proposed solution. The proposed method of recycling could lead to industrial use, which requires consistent sorting of waste electrical and electronic equipment.
\end{abstract}

\section{Introduction}

In recent years with the development of consumer electrics the recycling of electric waste has become a necessity the due to the lowering prices of electrics we experience its massive consumption as well as decrease of its lifetime. Retired electrics normally used to end in the solid and hazardous waste landfills. Because these products contain many valuable components, but also materials that are harmful to the environment, we have focused our work on the possibilities of reuse of the retired electric waste, originating mainly from computing technologies, as a source of valuable raw materials.

Electric waste is currently the fastest growing type of the waste. Globally it now constitute up to $5 \%$ of weight of the solid domestic waste which is almost as much as plastic packaging. In the European Union countries, where households annually produce about 8 million tons of electric waste, the electric waste is growing at a rate of $3-5 \%$ per year, almost three times faster than the total waste volume. Developing countries even assume that their electric waste production will triple by 2010 .
Experts estimate that in line with the growth in sales of electrics the European Union will have to cope with almost 11 million tons of the electric waste just in 2020 . Ten years later the annual production will rise to almost 14 million tons. And we must add to this another approximately three million tons of the electric waste originating from organizations and companies [1].

According to the latest information there is currently used about one billion of personal computers in the world. Independent analytic company Gartner expects that this number will double over the next six years [2]. According to this study the sales of computers will increase by $12 \%$ worldwide per year. However in the calculation of this growth it is necessary to calculate the depreciation of old models. As the study says about 180 million of personal computers (PCs) will be replaced this year, which will be $16 \%$ of all the systems used. A fifth of them will be completely destroyed and the rest could still be used for other purposes, or travel to less developed countries.

It is assumed that in the Czech Republic is used about $5.10^{6}$ personal computers. This means that considering the average lifetime of 11 years are

* Corresponding author: janacova@,fai.utb.cz 
discarded annually about $1,8.10^{4}$ personal computers, which involves, at an average weight $24 \mathrm{~kg}$ of the personal computer, the 432 tons of recyclable material. This will worsen over the time because population in the world is increasing and so does the consumption of products, while the lifetime of their use dramatically reduced. Probably the most valuable raw materials that can be obtained from the electric waste and specifically from the computers are the precious metals.

\section{Material of the printed circuit board (PCB)}

For surface mounting the PCB material should have coefficient of linear expansion approximately the same as the material of the components used. Otherwise, due to the different thermal expansion of circuit boards and components the excessive mechanical stress on the solder joint could develop. The size of the mechanical stress is yet derived from the difference of coefficients of the linear expansion. Secure mounting of the components doesn't depend only on their size, but for example also on temperatures in the operation of the final device, in particular on the limit temperatures during operation and on changes of ambient temperature. The resistance of the soldered joints to breakage depends also on their shape. The resistance to breakage of the soldered joints depends on its shape. In some cases it is necessary to use specially adapted PCBs. Based on experience during normal application of surface mounting on glass-epoxy PCB (FR4) without the risk of subsequent cracking of soldered joints there can be fitted miniature passive components (resistors, ceramic capacitors) up to $10 \mathrm{~mm}$, Integrated circuits design SO, plastic chip carrier, flat pack circuits, quad pack, TAB (Micropack) etc. It is not recommended to mount ceramic chip carrier which's coefficient of linear expansion doesn't correspond to the coefficient of linear expansion of the boards $[3,4,9]$.

Thicknesses of PCBs are not different from conventional embodiments. Currently the European producers offer plates with thicknesses from 0.8 to 3.2 $\mathrm{mm}$, a preferred size is $1.6 \mathrm{~mm}$. Copper foil is produced in thicknesses of 35 microns, 70 microns and 105 microns or more. FR4 material is supplied with a copper foil with a thickness of 18 micron, 9 micron and 5 micron. These thinnest films are used for the finest joints which is the case of some special applications of surface mount $[3,4,6]$.

\section{Theory}

The following figure shows the status of materials during the temperature change. It is evident that the expansion of the material 1 is much smaller than in the material 2 . This is due to the different coefficients of thermal expansion of both materials. We used this property to derive a formula for the calculation of the resulting shear stress which is needed for separation of the conductive paths and plastic materials from the PCB.

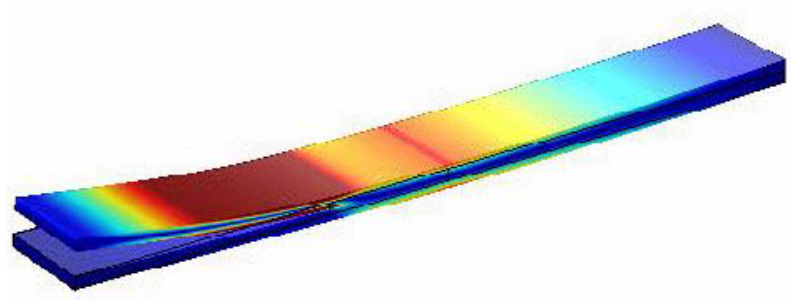

Fig. 1. Linear expansion of materials.

To calculate the amount of shear stress needed to split the two boards we used the Hook's law.

$$
\sigma=E \cdot \varepsilon
$$

where $\sigma$ is the resulting shear stress $[\mathrm{Pa}]$,

$\mathrm{E}$ is modulus of elasticity $[\mathrm{Pa}]$, $\varepsilon$ is the relative elongation [-].

In the final equation it is necessary to take into account the thermal expansion of solid objects.

$$
l=l_{0} \cdot(\alpha \cdot \Delta T+1),
$$

where $\alpha$ is the coefficient of linear expansion $\left[\mathrm{K}^{-1}\right]$, $\Delta T$ is the temperature difference $[\mathrm{K}]$,

$l_{0}$ is the original length of the material $[\mathrm{m}]$.

By modifying and merging the two equations we get the following equation for calculation of the shear stress of one plate.

$$
\sigma=E \cdot \alpha \cdot \Delta T
$$

Resultant force $F_{T}$ can be specified

$$
F_{T}=\left(\sigma_{1}-\sigma_{2}\right) \cdot S_{j}
$$

Where $F_{T}$ is a resultant force [N],

$\sigma_{1}$ is tensile stress of the first material [Pa],

$\sigma_{2}$ is tensile stress of the second material [Pa],

$S j$ is the contact surface of both materials $\left[\mathrm{m}^{2}\right]$.

This force must be greater than the allowable shear stress for the materials, which gives the following relationship:

$$
\frac{F_{T}}{S_{j}}>\tau_{s},
$$

where $\tau_{s}$ is the maximum allowable shear stress of the material $[\mathrm{MPa}]$.

For the calculation we selected the combination of epoxy resin and copper [5]. 
Calculation shows the size of the force in dependence on change of the temperature which is required to peel the copper surface paths from the epoxy resin.

The required shear stress for separation of $\mathrm{Cu}$ path from $\mathrm{PCB}$ is $109^{\circ} \mathrm{C}$.

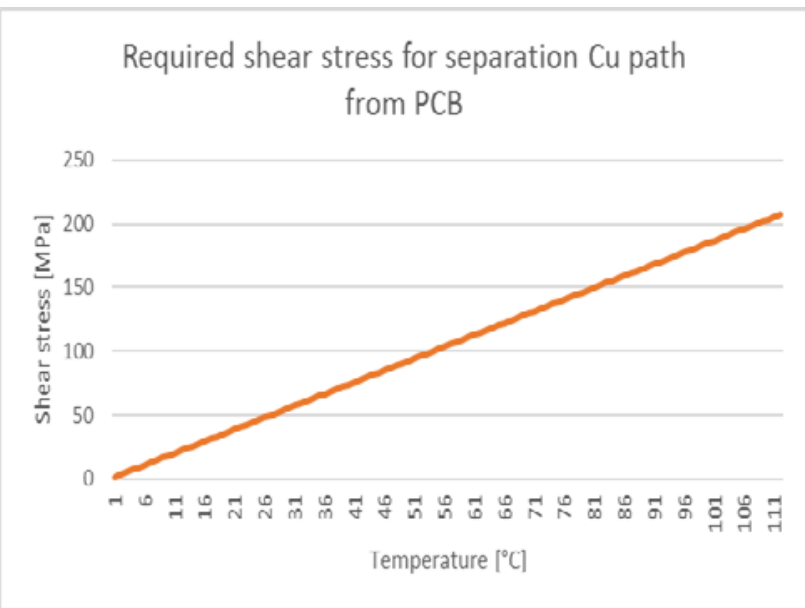

Fig. 2. Required shear stress for separation $\mathrm{Cu}$ path from $\mathrm{PCB}$.

Table 1. Mechanical properties of materials [5]

\begin{tabular}{|c|c|c|}
\hline & FR4 & Copper \\
\hline$E(\mathrm{~Pa})$ & $22 \cdot 10^{9}$ & $11 \cdot 10^{10}$ \\
\hline$\alpha\left(\mathrm{K}^{-1}\right)$ & $18 \cdot 10^{-6}$ & $17 \cdot 10^{-6}$ \\
\hline
\end{tabular}

\section{Modelling of transient thermal stress of layered plastic plates copper (Cu-EP) due to thermal shock}

\subsection{Thermal stress of multilayer walls composed of isotropic layers}

The influence of temperature changes on the inhomogeneous, layered plates/shells are generally manifested in two ways. If there is any (even homogeneous) body statically stored indefinitely, preventing the imposition of free thermal expansion of the body, creating a corresponding strain. For multilayer walls thermal stress occurs as a result of the inhomogeneity, when the thermal expansion in equidistant surfaces of walls into the generally different thermal expansion coefficients in the layers.

Consider the generally layer wall, for example the wall with generally variable properties after thick, exposed thermal effects of any temperature profile $\Delta T(x)$, corresponding to a certain point transient of heat transmission of the wall.

Not only the elastic constants, but the coefficient of linear thermal expansion is generally varies discontinuously at the interface of both layers as well as continuously within each of the layers, due to any dependence of these parameters on the temperature.

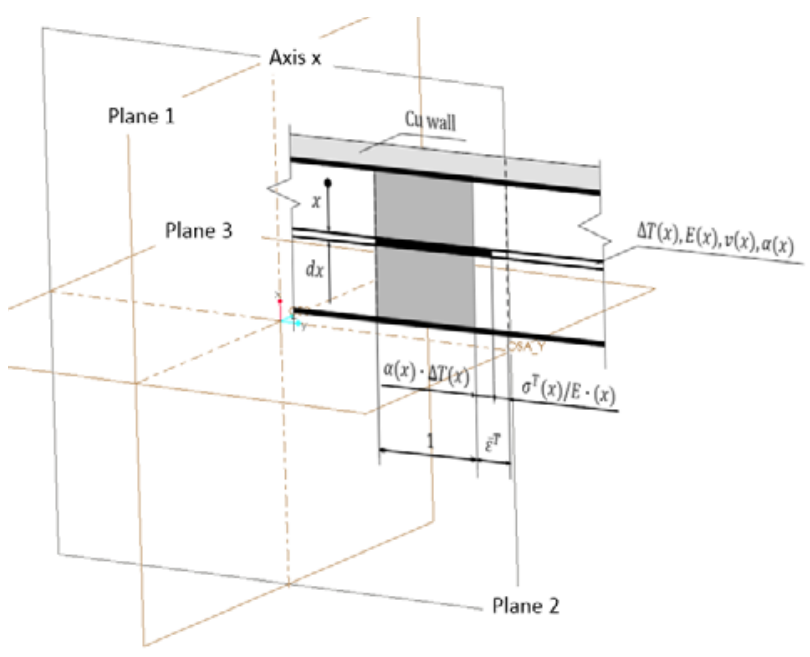

Fig. 3. Thermal stress of multilayer walls

On the case under consideration as can be seen on the wall as "thinking" composed from an infinite of the number of elementary layers of thickness $d y$. Each layer has its own values of the elastic constants and the thermal expansion coefficient. Value $\Delta T(x)$, express the difference of the actual temperature at the point " $x$ " and reference temperature of the wall, i.e. the temperature at which assume zero stress of the wall.

Let wall is mounted so that it is prevented only warping, while membrane deformation - i.e. a deformation in the direction of the reference plane are enabled. Externally so the wall will show some overall effective dilatation $\varepsilon^{T}$, assuming of isotropy is the same in both directions of the coordinate system $(y, z)$ of reference plane. The resulting membrane forces in the cross-sections of the wall is equal to zero, then the equation is:

$$
\int_{(s)} \sigma^{T}(x) d x=0
$$

If no warping of the wall is the sum of thermal expansion and elastic deformation of each imaginary elemental layer $\mathrm{dx}$ constant, It is equal to the effective value $\varepsilon^{T}$. Considering that it is a equibiaxial stress is:

$$
\varepsilon^{T}=\frac{\sigma^{T}(x)}{E^{*}(x)}+\alpha(x) \Delta T(x)
$$

where: $E^{*}=E /(1-v)$.

Using (1) can be expressed in the resulting of unibiaxial deformation of the wall. Equation

$$
\varepsilon^{T}=\frac{\int_{(s)} E^{*}(x) \alpha(x) \Delta T(x) d x}{\int_{(s)} E^{*}(x) d x} .
$$


Thermal stress $\sigma_{x}^{T}=\sigma_{z}^{T}$ in the area of the ordinate $y$ will be:

$$
\sigma^{T}(x)=E^{*}(x)\left[\varepsilon^{T}-\alpha(x) \Delta T(x)\right]
$$

Equation (9) defines stress in the equidistant planes with the plate of plane, except the edges where it is necessary to solve the corresponding boundary value problem. Are not expressed as normal and interlaminar shear stresses which representing the local stress concentrations at the edges of the layers.

\subsection{FEM modeling of transient thermal stress}

Diagrams of shear stresses are plotted in figure 4. Unlike normal interlaminar component the sign peak shear stress does not play any role for subsequent separation of the layers. How to heating and a subsequent rapid cooling the layered structure to cause formation of significant stress peaks, which can cause separation of the layers, applying in the recycling process.

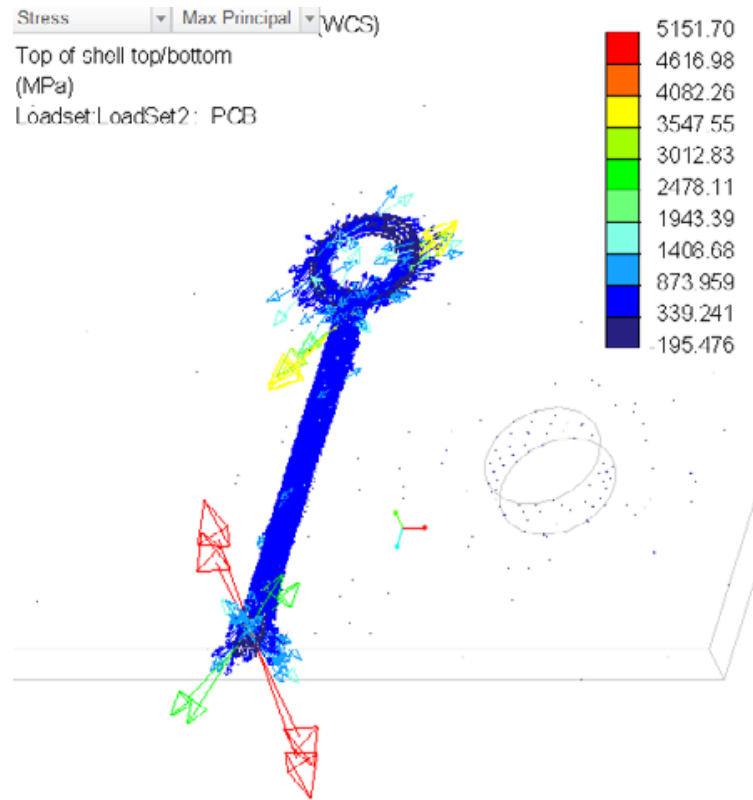

Fig. 4. Shear stress in the copper path of $\mathrm{PCB}$ - display type vectors.

Based on the results of the modeling of transient thermal stress of PCBs is possible to comment on potential uses of these stress for the separation of the $\mathrm{Cu}$ layers in the process of recycling computer waste. The chosen procedure tempering and rapid cooling you can rate depending on the parameters (temperature, residence time) in terms of the level interlinear stress and thus its effectiveness.

\section{Laboratory tests}

Hot air gun has been use for the most effective heating to $370^{\circ} \mathrm{C}$. The temperature was measured contactlessly using radiometer Thermopoint 64/64 plus, having a range from -30 to $900^{\circ} \mathrm{C}$. The temperature is sufficient even for the separation of a tin. After using mechanical separation components dropped away from the PCB. We used mechanical separation and when you delete the conductive paths. This separation is effective, but in newer types of PCB was necessary for the separation of the copper paths applied more thermal shocks $[5,10]$.

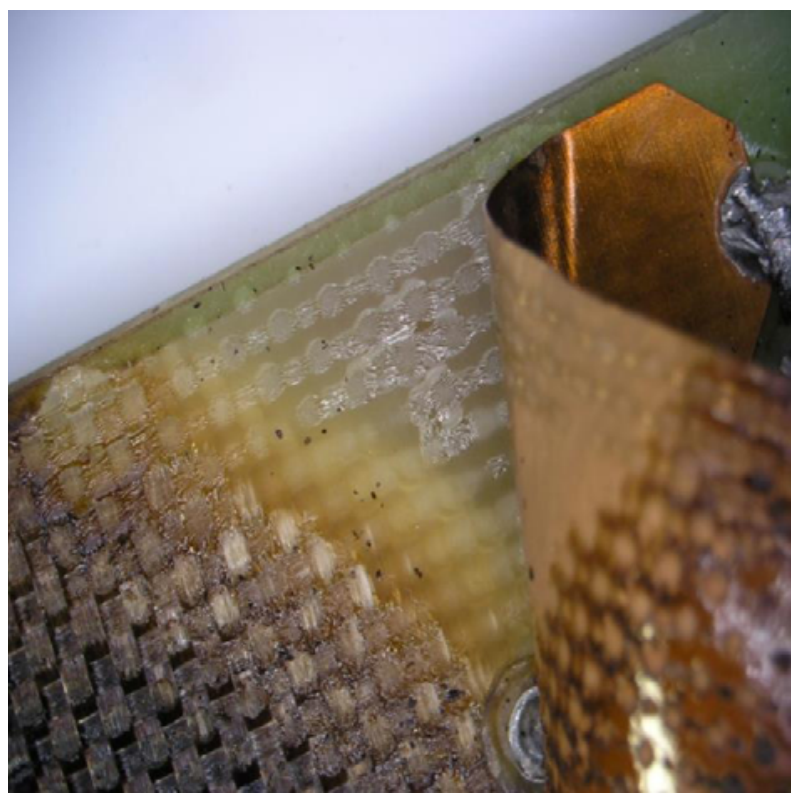

Fig. 5. PCB after heating to temperature $370^{\circ} \mathrm{C}$.

\subsection{Results of separation shown under microscope}

Photos of separating copper paths from the $\mathrm{PCB}$ in the separation in the laboratory.

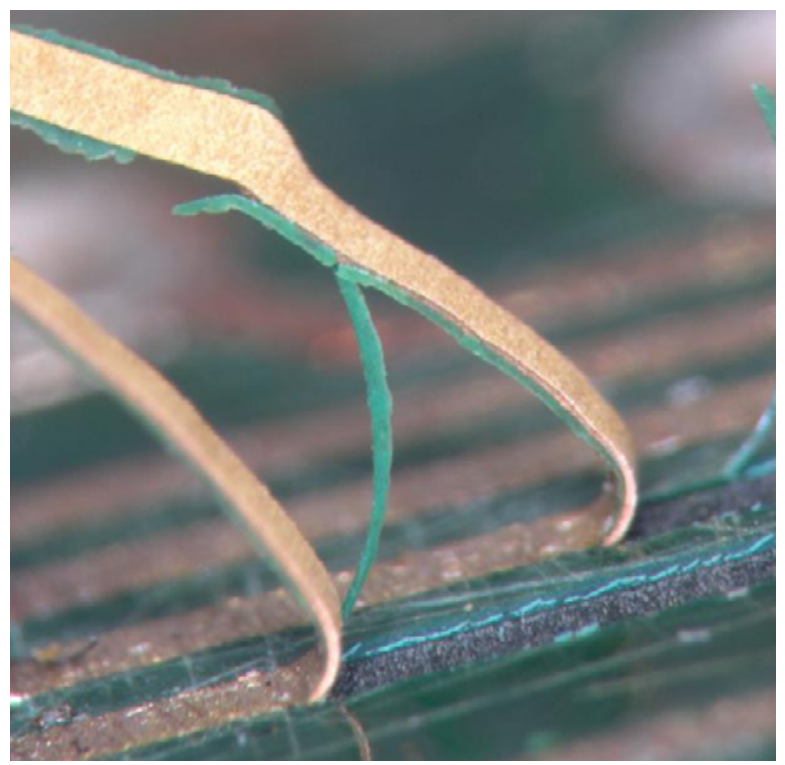

Fig. 6. Detailed view of the separated copper path under the microscope. 


\section{Conclusion}

We conducted a study of the production of printed circuit board, to be able to choose a suitable way of separation electric waste. Furthermore we calculated the size of the shear stress that is necessary to separate the conductive copper paths from epoxy resin. In our own experiments we have used several methods of heating of the PCB. Heating PCB at a press tempered at $200{ }^{\circ} \mathrm{C}$, further microwave heating. Was the most effective heating with a heat gun to $350{ }^{\circ} \mathrm{C}$. This temperature is sufficient even for the separation of tin, because the melting point of tin is $250^{\circ} \mathrm{C}$. After using mechanical separation, parts dropped away from the PCB. We used a mechanical separation when you delete the conductive paths.

Laboratory tests showed that the temperature difference must be much greater than the calculation gives. It is due to the fact, that copper is very plastic and the calculated expansion caused by the temperature difference is smaller than expected. For newer types of PCB it was necessary inject more thermal shocks for the separation of the copper paths.

The proposed method of recycling could lead to industrial use, which requires prior diligent sorting of the electric waste.

\section{Acknowledgement}

The research work is supported by the Project of the Structural Funds of the EU, Operational Programme Research and Development, Measure 2.2 Transfer of knowledge and technology from research and development into practice and by the Ministry of Education, Youth and Sports of the Czech Republic within the National Sustainability Programme project No. LO1303 (MSMT-7778/2014) and also by the European Regional Development Fund under the project CEBIA-Tech No. CZ.1.05/2.1.00/03.0089

\section{References}

1. Ekoabeceda (in Czech) [Online]. [cit. 2017-02-10]. Available from: http://www.recyklohrani.cz

2. Recycling (in Czech) [Online]. [cit. 2017-02-10]. Available from: http://ekologie.xf.cz

3. F. Božek, R. Urban, Z. Zemánek, Recycling, 202 p. (in Czech), ISBN 80-238-9919-8 (2002)

4. Volek, J., Pospíchal, Z.: Technický týdeník, 48, č. 25. p. 8-9, ISSN 0040-1064 (2000)

5. J. Křenek, Diploma work, (in Czech) FAI UTB, Zlín (2007)

6. D. Beneš, Waste, http://www.waste.cz/pdf/ (2007)

7. M. Noska, Gartner: http://computerworld.cz/, (2008)

8. P. Božek, In., ICSS 2013; Wroclaw; Poland; p. 229240. ISSN 2194-5357. (2013)
9. P. Michal, M. Gombár, A. Vagaská, J. Pitel', J. Kmec. In Advanced Materials Research, 712, p. 382-386. Trans Tech Publications. (2013)

10. M. Maňas, D. Maňas, M. Staněk, M., Š. Šanda, V. Pata, Chemicke listy. (2011) 